\title{
Tratamento da Superfície de Cateteres de Poliamida 11 por Plasma de Oxigênio
}

\author{
Gean V. Salmoria \\ Laboratório CIMJECT, Departamento de Engenharia Mecânica, UFSC \\ Waldemar F. M. Martins, Debora M. Fúcio \\ Nano Endoluminal S.A
}

\begin{abstract}
Resumo: A poliamida 11, assim como grande parte dos polímeros empregados na construção de dispositivos minimamente invasivos de uso médico, não apresenta significativa interação com líquidos polares, o que limita seu uso em algumas aplicações, uma vez que a maioria dos tecidos biológicos internos apresenta caráter hidrofílico (alta afinidade por água). No presente trabalho, investigou-se a influência do processo de tratamento por plasma de oxigênio da superfície da poliamida 11 sobre a composição, rugosidade e a hidrofilicidade. Através do tratamento, as características do material foram alteradas de forma a favorecer a adesão de uma camada polimérica hidrofílica sobre sua superfície, aumentando a hidrofilicidade e, consequentemente, a biocompatibilidade do dispositivo polimérico. Cateteres de poliamida 11 foram submetidos a diferentes tempos de exposição ao plasma, gerado sob uma atmosfera de oxigênio com pressão, temperatura e voltagem constante. Para isso, foram realizadas análises de espectroscopia de infravermelho, microscopia eletrônica de varredura e medida do ângulo de molhamento por água na superfície do polímero. As amostras tratadas e não tratadas (controle) foram caracterizadas e constatou-se um aumento na rugosidade e no ângulo de contato, indicando uma possível melhora da aderência da camada polimérica hidrofílica a ser depositada.
\end{abstract}

Palavras-chave: Cateteres PA11, tratamento superfície, plasma de oxigênio.

\section{Surface Treatment of Polymide 11 Catheters by Oxygen Plasma}

Abstract: Polyamide 11, as well as the great majority of polymers used in the construction of minimally invasive devices for medical use, shows no significant interaction with polar liquids, which limits its use in some applications, since most of internal biological tissues have hydrophilic character (high affinity for water). In this study, an investigation was made of the influence of oxygen plasma treatment of polyamide 11 surface on the composition, roughness and hydrophilicity. Through the plasma treatment, the polymer characteristics were changed to promote adhesion of a hydrophilic polymer layer on its surface, increasing the hydrophilicity and, consequently, the biocompatility of the polymeric device. Polyamide 11 catheters were submitted to different times of exposure to plasma, generated in an oxygen atmosphere with pressure, temperature and constant voltage. The treated and untreated (control) samples were then characterized using infrared spectroscopy, scanning electron microscope and contact angle measurements with water. Both the roughness and contact angle increased with the plasma treatment, indicating a possible improvement of the adherence of the hydrophilic layer coating the polymer.

Keywords: PA11 catheters, surface treatment, oxygen plasma.

\section{Introdução}

A incorporação de procedimentos minimamente invasivos à prática cirúrgica de forma geral tem proporcionado a médicos e, principalmente, a pacientes muitas facilidades e benefícios frente às tradicionais técnicas equivalentes. Por meio de pequenas incisões localizadas e de equipamentos específicos, o manuseio cirúrgico fica restrito apenas à área doente, preservando assim as estruturas periféricas. Com isso, reduz-se a necessidade de reposição de sangue, diminui-se o tempo de internação, a probabilidade de infecções, as dores pós-operatórias, entre outras vantagens ${ }^{[1]}$. Por outro lado, estas novas técnicas também apresentam algumas desvantagens. Tratandose dos procedimentos endovasculares (também classificados como minimamente invasivos), por exemplo, um dos maiores problemas enfrentados são os traumas e lesões causados às paredes dos vasos sanguíneos devido à fricção do dispositivo (cateter) durante sua introdução ${ }^{[1]}$. Alguns recursos tecnológicos na área dos materiais têm ajudado na diminuição desses danos, como por exemplo, por meio da aplicação de uma camada polimérica hidrofílica sobre a superfície do polímero utilizado no dispositivo. Materiais hidrofílicos são polares e apresentam grande afinidade com líquidos de mesmo caráter, como o sangue, tornando a interface entre eles altamente deslizante ${ }^{[2]}$. Além disso, a aplicação da camada polimérica hidrofílica mostra resultado 
positivo em ensaios como citotoxicidade, toxidade sistêmica, reatividade intracutânea aguda, entre outros, comprovando que suprem também exigências associadas a biocompatibilidade ${ }^{[1]}$. De forma geral, a obtenção de um revestimento polimérico hidrofílico sobre o dispositivo polimérico (no caso o cateter) pode ser dividida em: tratamento de superfície do dispositivo, deposição do revestimento e cura. Dentre estas etapas, o tratamento se faz necessário, em função, sobretudo, da diferença de polaridade comumente apresentada entre a camada de polímero hidrofílico e o polímero usado como substrato, e consequentemente da baixa energia livre de superfície dos principais polímeros utilizados em cateteres, fatores esses que dificultam a adesão entre eles.

Um dos processos que vem sendo amplamente utilizado e tem se mostrado efetivo na modificação de propriedades de superfície dos materiais, tais como coeficiente de fricção, molhabilidade, adesão e biocompatibilidade, é o tratamento por plasma de oxigênio $^{[3,4]}$. Nessa técnica a superfície do dispositivo é submetida ao bombardeamento de um feixe iônico criado por um campo elétrico de alta tensão sob uma atmosfera de baixa pressão. $\mathrm{O}$ choque entre espécies reativas de elementos do gás e o material promove a quebra de ligações químicas e o surgimento de radicais livres, que por sua vez permitirão a formação de grupos funcionais polares na superfície tratada ${ }^{[5]}$, aumentando assim a energia livre de superfície do substrato ${ }^{[6]}$. Essa formação de grupos funcionais na superfície do polímero substrato promove a interação com a camada de polímero hidrofílico através de ligações secundárias, auxiliando assim na aderência da mesma ${ }^{[7,8]}$. A molhabilidade é a habilidade de um líquido de aderir (molhar) um sólido espalhando-se ao longo de sua superfície em diferentes graus. Quando o liquido é a água, um aumento da molhabilidade se relaciona diretamente com um aumento do grau de hidrofilicidade do material ${ }^{[9]}$.

O tratamento de superfície por plasma de oxigênio pode promover também um aumento da rugosidade superficial e alteração na área de contato ${ }^{[10]}$. O tratamento por plasma é adequado para recobrimento uniforme de dispositivos tridimensionais, dispensando a necessidade de um complexo sistema de manipulação do alvo perante o feixe. Além disso, as propriedades de volume do polímero tratado não são afetadas, uma vez que as modificações se estendem a uma pequena profundidade abaixo da superfície ${ }^{[11-15]}$

O objetivo deste trabalho consistiu na análise da influência do tempo de exposição ao tratamento por plasma de oxigênio sobre a molhabilidade da superfície de cateteres de poliamida 11 e a influencia deste processo na deposição de revestimento hidrofílico. Esse polímero é recomendado para fabricação de dispositivos médicos minimamente invasivos por apresentar flexibilidade, leveza, boa resistência mecânica, além do custo relativamente baixo de produção. As técnicas de caracterização empregadas para as análises nesse experimento foram a análise goniométrica, a microscopia eletrônica de varredura e a espectroscopia de infravermelho com transformada de Fourier por reflectância (FTIR).

\section{Experimental}

\section{Materiais}

O substrato utilizado nesse estudo trata-se da poliamida 11 (PA11). Esse polímero possui ponto de fusão por volta de $184{ }^{\circ} \mathrm{C}$ e temperatura de trabalho na faixa de - 40 a $130{ }^{\circ} \mathrm{C}^{[14]}$. A PA11 foi utilizada em forma de cateteres, com comprimento de $1130 \mathrm{~mm}$, espessura de parede de $0,6 \mathrm{~mm}$ e diâmetro externo de $3,8 \mathrm{~mm}$. Os cateteres foram fornecidos pela empresa AP Extrusion Incorporated. Estes cateteres foram segmentados em corpos de prova com comprimento de $40 \mathrm{~mm}$ e limpos com álcool etílico de concentração $70 \%$ GL com o objetivo de remover qualquer substância existente na superfície que pudesse comprometer o processo de tratamento e, conseqüentemente, seu desempenho.

\section{Equipamento de plasma}

$\mathrm{O}$ reator utilizado nesse experimento encontra-se ilustrado esquematicamente na Figura 1. Basicamente, o sistema é constituído de uma câmara de aço inoxidável (1) em formato cilíndrico com volume aproximado de 12 litros, sobre uma bancada (2), lacrada por borracha de vedação (3) também em aço inoxidável e uma janela para inspeção da amostra (4). Ainda sobre a bancada, estão dois eletrodos cilíndricos de alumínio (5) com $13 \mathrm{~mm}$ de diâmetro e $400 \mathrm{~mm}$ de comprimento cada, distanciados em $270 \mathrm{~mm}$, e o suporte das amostras (6), também em aço inoxidável. $\mathrm{Na}$ bancada existem orifícios ligando o cilindro de oxigênio (8) e a entrada de oxigênio (9), a bomba de vácuo (10) e a saída de gás (11). Todo sistema é controlado por válvulas (12). Um sensor de pressão (13) do tipo membrana capacitiva, para medir a pressão interna, e um termopar (14) do tipo Cromel /Alumel, posicionado ao lado do suporte das amostras, foram utilizados para monitorar esses dados dentro da câmara durante o tratamento.

\section{Tratamento por plasma de oxigênio}

As amostras foram posicionadas a uma distância que garantiu que sua temperatura durante o tratamento estivesse dentro da faixa de trabalho específico, não sofrendo assim variações que pudessem ser atribuídas a exposição do material a temperaturas elevadas. Durante o experimento, a temperatura medida próxima à amostra ficou por volta de $100{ }^{\circ} \mathrm{C}$. Inicialmente, o reator era evacuado pela bomba de vácuo até que se atingisse uma pressão interna de aproximadamente $5 \times 10^{-2} \mathrm{~Pa}$. Posteriormente, o oxigênio era introduzido na câmara até a estabilização da pressão em $8 \times 10^{-1} \mathrm{~Pa}$. Entre os eletrodos, posicionados de forma capacitiva, foi aplicada uma tensão de $2000 \mathrm{~V}$ (60 Hz corrente alternada), formando uma descarga por plasma. Durante o experimento, os parâmetros de tensão, frequência, temperatura e pressão foram mantidos constantes, objetivando investigar a evolução do comportamento da superfície dos cateteres apenas com a variação do tempo de tratamento. Em virtude das peculiaridades dessa tecnologia, os intervalos de tempo precisaram ser estipulados através de avaliações preliminares. Os critérios adotados para a definição dos tempos de exposição foram: 


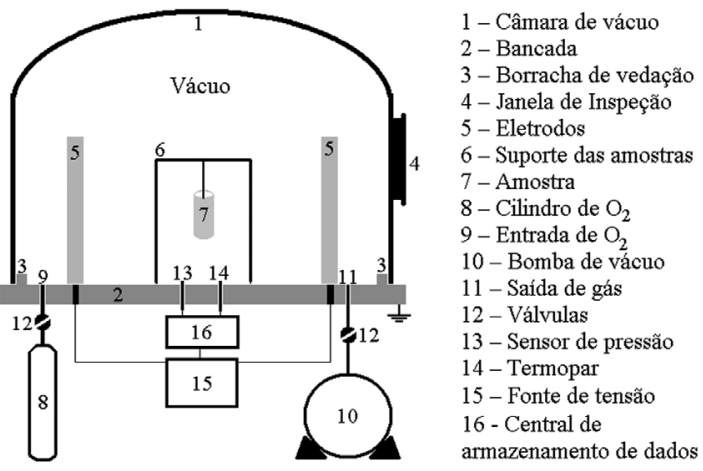

Figura 1. Representação esquemática do reator a plasma utilizado para tratamento da poliamida 11. Fonte: elaborada pelos autores.

- Otimizar a relação número de amostras e intervalo de tempo avaliado (com o intuito de auxiliar na viabilidade econômica do estudo);

- Abranger faixas de tempo para cada técnica na qual as amostras apresentassem na sua superfície desde alterações insignificantes até alterações extremas, próximas do limite de desuso do material (o limite adotado neste caso foi a alteração de cor, uma vez que aspectos estéticos são imprescindíveis para dispositivos da área da saúde).

Dessa forma se estabeleceu os tempos de exposição ao bombardeamento em $1,2,3,5$ e 8 minutos para cada conjunto de amostra. Amostras não tratadas foram utilizadas como amostra de controle.

\section{Caracterizações das amostras}

A análise goniométrica foi realizada em um equipamento Data Physics modelo OCA-15, operado em condições ambientes de temperatura e pressão. $\mathrm{O}$ ângulo de contato medido por esta técnica é aquele formado entre a superfície do sólido e uma das tangentes da superfície da gota que passa por qualquer ponto que separa os três estados do sistema, ou seja, líquido, sólido e gasoso (Figura 2).

Neste trabalho foram depositadas duas gotas de água deionizada por amostra e medidos dois ângulos de contato por gota, totalizando quatro medidas. As gotas continham 5,0 $\mu \mathrm{L}$ de volume e tiveram seus ângulos medidos 30 segundos após sua deposição (tempo de estabilização). A imagem da gota era capturada pela câmera de alta resolução do aparelho e um computador conectado ao sistema calculava automaticamente o valor desses ângulos através do software Image Tool. Com este parâmetro macroscópico é possível quantificar indiretamente características em nível microscópico da superfície em estudo, como a energia livre de superfície ${ }^{[1]}$ (baixos ângulos de contato estão associados a superfícies sólidas com alta energia livre). A técnica de goniometria foi empregada para todos os tempos e exposição, bem como para uma amostra não tratada (controle).

Para a análise do relevo das amostras tratadas, utilizouse o Microscópio Eletrônico de Varredura XL-30 da Philips. Antes do procedimento para essa caracterização todas as amostras foram recobertas com uma fina camada

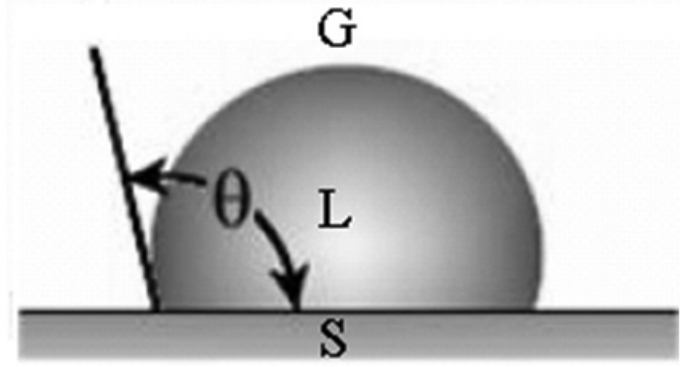

Figura 2. Método da gota séssil para determinar o ângulo de contato. Fonte: elaborada pelos autores.

de $20 \mathrm{~nm}$ de ouro no metalizador Bal-Tec modelo CED 030 a fim de melhorar a definição dos contrastes. Os aumentos de imagens da superfície para esse estudo foram de 50, 500, 3000 e 5000 vezes. Como medida de controle da variação da textura dos cateteres, amostras não tratadas também foram inspecionadas.

A análise de infravermelho pela técnica de espectroscopia de infravermelho com transformada de Fourier por reflectância (FTIR) foi realizada com o espectrofotômetro Perkin Elmer FT-IR modelo 16PC, que varreu uma região entre 4000 até $400 \mathrm{~cm}^{-1}$, com resolução de $4 \mathrm{~cm}^{-1}$. Essa análise foi realizada nas amostras tratadas e não tratadas a fim de identificar possíveis alterações químicas sofridas pelo material após o tratamento, como, por exemplo, o surgimento de novos grupos funcionais.

\section{Resultados e Discussões}

A partir dos resultados da analise goniométrica, construiu-se o gráfico da Figura 3, que apresenta os ângulos de contato formados entre gotas de água e a superfície da PA11 em função dos tempos de exposição ao tratamento de plasma. Como pode ser observado pelo comportamento da curva, houve uma redução gradual dos valores desses ângulos conforme o tratamento evoluiu. A amostra não tratada está representada no tempo zero (ângulo de contato de $84^{\circ}$ ). $\mathrm{O}$ tratamento se mostrou mais efetivo durante o primeiro minuto, notado pela queda mais acentuada do ângulo $\left(65^{\circ}\right)$. Após esse período, a curva segue uma tendência de regressão linear até o último tempo estabelecido, o qual apresentou o menor ângulo $\left(51^{\circ}\right)$. Um dos fatores que justificaria essa diminuição dos ângulos seria a inserção de grupamentos com oxigênio (C-O, $\mathrm{C}=\mathrm{O}, \mathrm{OH})$ e o aumento da energia de superfície, aumentando a interação da gota depositada sobre o cateter $^{[6]}$. A existência de ligações secundárias tipo dipolodipolo e ligações de hidrogênio faria a gota espalhar e molhar a superfície ${ }^{[6]}$. Tempos mais prolongados sugerem que esses ângulos tenderiam a diminuir ainda mais. Contudo, em avaliações prévias, tempos de exposição superiores a 8 minutos comprometeram, sobretudo, $\mathrm{o}$ aspecto visual das amostras, tornando-as opacas e amareladas, inviabilizando seu uso em dispositivos para aplicações médicas. Logo, a perspectiva de melhores resultados para o plasma em tempos maiores pode ser descartada. Os desvios padrão das médias dos valores de ângulos estão representados no próprio gráfico.

A Figura 4 mostra micrografias de MEV da superfície de amostras tratadas e não tratadas com a ampliação que gerou a melhor definição das imagens (5000 vezes). 
Na Figura 4a, a amostra de controle apresentou uma superfície plana com algumas leves ranhuras, provocadas durante o manuseio do material. Nas micrografias das Figuras $4 \mathrm{~b}$ e $4 \mathrm{c}$, correspondentes às amostras dos tempos

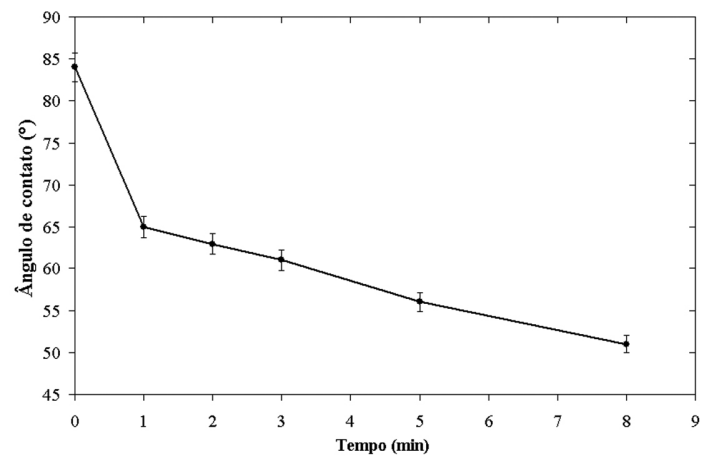

Figura 3. Gráfico dos ângulos de contato em função do tempo de exposição ao tratamento via plasma.
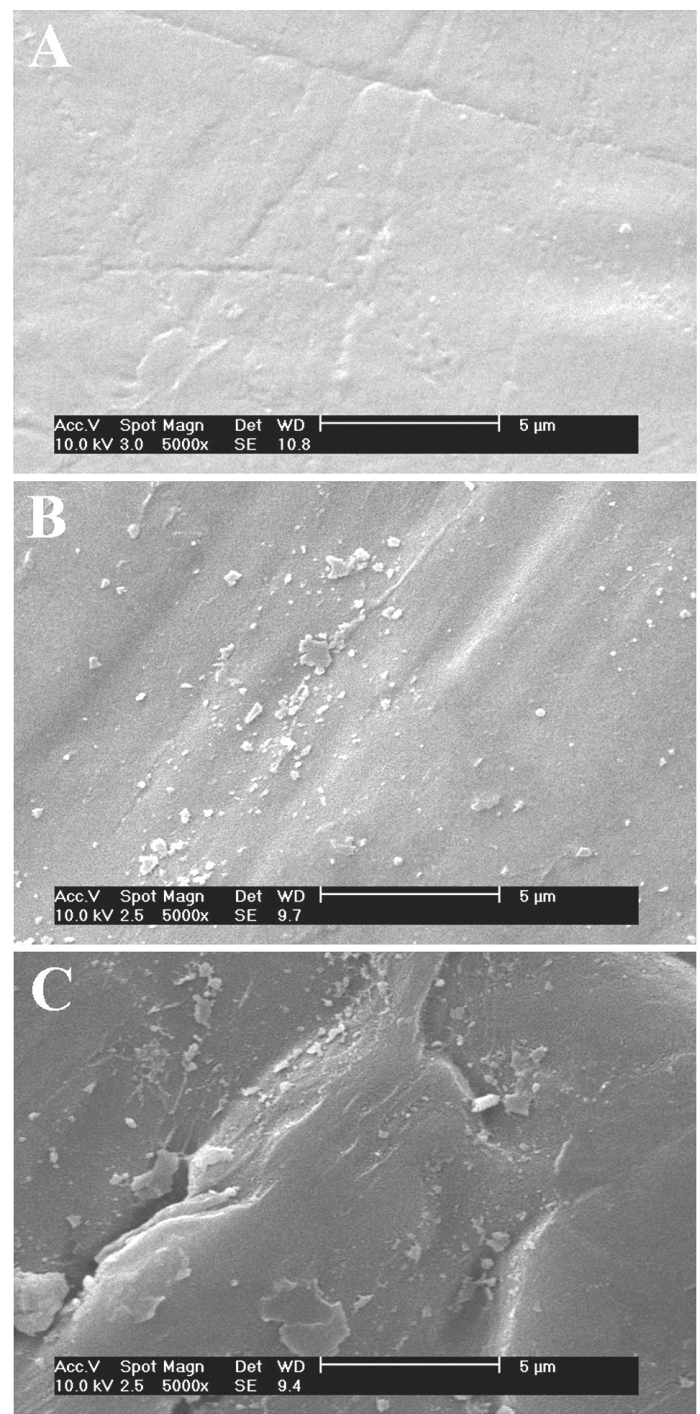

Figura 4. Micrografias das superfícies das amostras de PA11 tratada por plasma de oxigênio por: a) 0 min (não tratada), b) 3 min e c) 8 min. de 3 e 8 minutos, é possível notar mudanças significativas na textura das superfícies com o surgimento de rugosidades, que se intensificaram a medida que o tempo de exposição ao tratamento aumentou. Este fenômeno contribuiu para o aumento da molhabilidade (confirmada anteriormente pela análise goniométrica), devido ao surgimento de desníveis no relevo, que ampliaram a área total de contato e ,consequentemente, aumentaram a energia livre de superfície ${ }^{[1,3]}$. As imagens de amostras submetidas ao tratamento em intervalos de tempo menores, entre 1 e 3 minutos de exposição, e de menores resoluções, 50, 500 e 3000 vezes, não evidenciaram uma sensível evolução nas alterações de superfície que fossem claramente perceptíveis quando comparadas.

$\mathrm{Na}$ Figura 5 observam-se dois espectros de infravermelho gerados pela técnica FTIR, um da amostra não tratada (Figura 5a) e da amostra tratada por 60 segundos (Figura 5b), tempo que apresentou as modificações mais significativas tanto na diminuição do ângulo de contato quanto no aumento rugosidade. Os picos nas bandas intensas de absorbância correspondentes a ligações químicas ou grupos funcionais presentes na estrutura molecular da PA11 estão entre 3500 e $1200 \mathrm{~cm}^{-1[12]}$. Na Figura 5a, as bandas em $2953 \mathrm{e}$ $2923 \mathrm{~cm}^{-1}$ correspondem à deformação axial assimétrica das ligações $\mathrm{C}-\mathrm{H}$ dos grupos $\mathrm{CH}_{3}$ e $\mathrm{CH}_{2}$, respectivamente. Já a banda em $2854 \mathrm{~cm}^{-1}$ é referente à deformação axial simétrica de ligações C-H do grupo $\mathrm{CH}_{2}$ e em $1713 \mathrm{~cm}^{-1}$
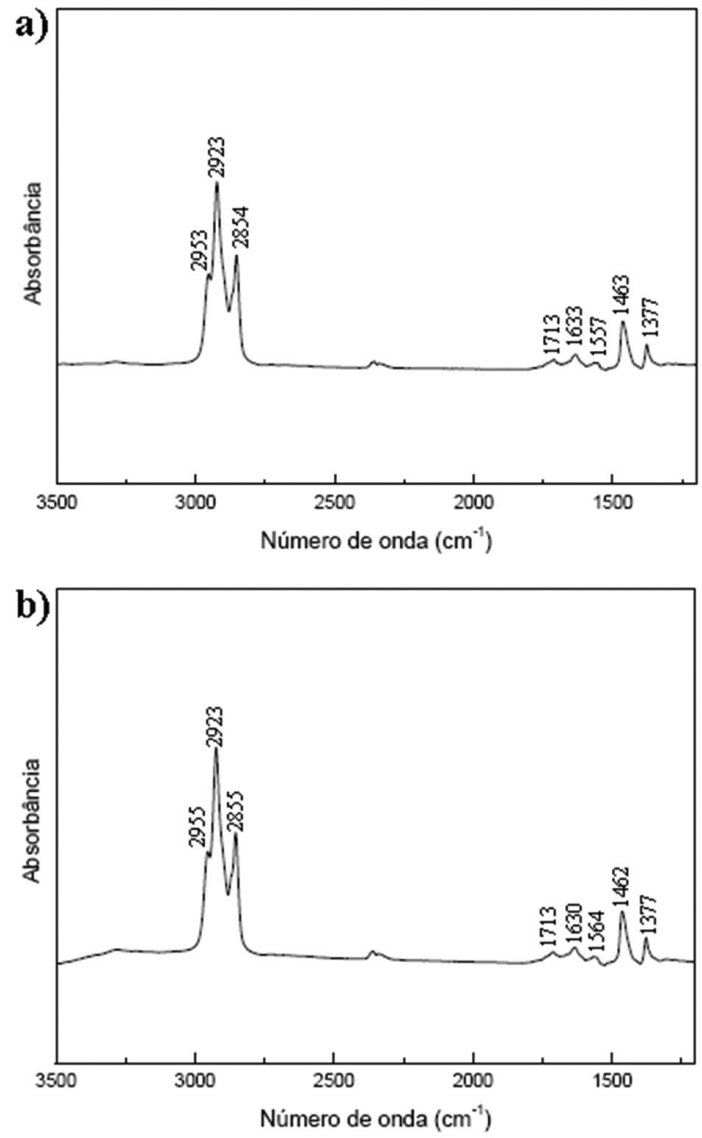

Figura 5. Espectros de infravermelho das amostras: a) não tratada; b) tratada por plasma de oxigênio por $8 \mathrm{~min}$. 
trata-se da vibração de deformação axial de $\mathrm{C}=\mathrm{O}$. Em $1633 \mathrm{~cm}^{-1}$ observa-se a banda correspondente à vibração de deformação axial de $\mathrm{C}=\mathrm{O}$ (banda de amida $\mathrm{I}$ ) e em $1557 \mathrm{~cm}^{-1}$ à vibração de deformação angular do N-H (banda de amida II). A banda em $1463 \mathrm{~cm}^{-1}$ refere-se à deformação angular simétrica do $\mathrm{CH}_{2}$ e a banda em $1377 \mathrm{~cm}^{-1}$ à deformação angular simétrica do $\mathrm{CH}_{3}$. Comparando-se ambos os espectros, é possível notar, para as amostras tratadas, que não ocorreram variações significativas nos valores dos picos característicos da PA11, apenas algumas mudanças nos números de onda de 2953 para 2955, 1633 para 1630, 1557 para 1564 e de 1463 para $1462 \mathrm{~cm}^{-1}$. Constata-se que a técnica de FTIR é limitada para perceber mudança na composição química da superfície do material quando essas forem pequenas em relação ao volume total (largura do feixe versus penetração do feixe) de amostra analisada pelo feixe de infravermelho, sendo a medida por goniometria mais sensível a estas modificações na composição da superfície.

\section{Conclusões}

O tratamento de superfície de poliamida 11 através do processo por plasma de oxigênio, nas condições desse estudo, mostrou-se adequado para a preparação da superfície de cateteres desse material para a deposição de uma camada de polímero hidrofílico biomédico, uma vez que esta técnica de tratamento gerou modificações na polaridade da superfície do material, evidenciado nas medidas por goniometria. Pode-se observar que alterações físico-químicas na superfície, como o aumento da rugosidade confirmada pelas imagens de MEV, e as alterações químicas na composição, evidenciadas em medidas por goniometria, ocorreram nas amostras tratadas, confirmando a eficácia do tratamento para alteração nas propriedades da superfície da PA11. A análise do ângulo de contato permitiu constatar também que as alterações de superfície foram diretamente dependentes do tempo de exposição ao plasma e que o tratamento de 8 minutos apresentou o resultado considerado mais interessante para a aplicação desejada, i.e. ângulo de $51^{\circ}$.

\section{Agradecimentos}

Os autores agradecem a empresa Nano Endoluminal S.A., por financiar em parte este trabalho, ao $\mathrm{CNPq}$ e a FAPESC no âmbito do programa PRONEX.

\section{Referências Bibliográficas}

1. Laporte, R. J. - "Hydrophilic Polymer Coatings for Medical Devices: Structure/Properties, Development, Manufacture and Applications", Technomic, Claremont (1997).

2. Baijal, M. D. - "Plastics Polymers Science and Technology", John Wiley \& Sons, New York (1982). PMid:6818906.

3. Costa, T. H. C.; Feitor, M. C.; Alves, J. C.; Freire, P. B. \& Bezera, C. M. - J. Mater. Process. Technol., 173, p.40 (2006). http://dx.doi.org/10.1016/j.jmatprotec.2005.11.008

4. Wertheirmer, M. R.; Fozza, A. C. \& Hollader, A. - Nucl. Instr. Meth. Phys. Res. B, 151, p.65 (1999).

5. Vohrer, U.; Muller, M. \& Oehr, C. - Surface Coat Technol., 98, p.1128 (1998). http://dx.doi.org/10.1016/ S0257-8972(97)00549-5

6. Song, J.; Gunst, U.; Arlinghaus, H. F. \& Vancso, G. J. - Appl. Surf. Sci., 253, p.9489 (2007). http://dx.doi. org/10.1016/j.apsusc.2007.06.018

7. Van Krevelen, D. W. - "Properties of polymers: their correlation with chemical structure; their numerical estimation and prediction from additive group contributions", Elsevier Science, Amsterdam (1997).

8. Ferrero, F. - Polym. Test., 22, p.571 (2003). http://dx.doi. org/10.1016/S0142-9418(02)00153-8

9. Acquarulo, L. A.; O'Neil, C. J. \& Nilajkar, A. S. - "Lubricious Compounds for Biomedical Applications Using Hydrophilic Polymers", World Intellectual Property Organization, Switzerland (2006).

10. Dorai, R. \& Kushner, M. J. - J. Phys., D. Appl Phys., 36, p.666 (2003). http://dx.doi.org/10.1088/00223727/36/6/309

11. Carrino, L., Maroni, G. \& Polini, W. - J. Mater. Process. Technol., 121, p.373 (2002). http://dx.doi.org/10.1016/ S0924-0136(01)01221-3

12. Silverstein, R. M.; Bassler, G. C. \& Morrill, T. C. - "Spectrometric Identification of Organic Compounds", John Wiley \& Sons, New York (1995).

13. Costa, T. H. C.; Feitor, M. C.; Alves Junior, C. \& Bezerra, C. M. - Matéria, 13, p.130 (2008).

14. Mark, J. E. - "Polymer Data Handbook", Oxford University Press, United Kingdom (1999).

15. Rangel, E. C.; Bento, W. C. A.; Rangel, R. C. C. \& Cruz, N. C. - Rev. Bras. Apl. Vacuo, 26, p.165 (2007)

Enviado: $10 / 04 / 12$

Reenviado: $26 / 09 / 12$ Aceito: $15 / 10 / 12$ 